See discussions, stats, and author profiles for this publication at: https://www.researchgate.net/publication/279192925

\title{
Dielectric Characterization at High Temperature of Iron Doped Potassium Strontium Niobate Ceramic by Impedance Spectroscopy
}

Article in Materials Science Forum · June 2015

DOI: 10.4028/www.scientific.net/MSF.820.187

\section{CITATIONS}

0

3 authors:

C. V. de Lima

Universidade Federal da Paraíba

3 PUBLICATIONS O CITATIONS

SEE PROFILE

S. Lanfredi

São Paulo State University

142 PUBLICATIONS 1,506 CITATIONS

SEE PROFILE
READS

73

Marcos Augusto Lima Nobre

São Paulo State University

184 PUBLICATIONS 1,239 CITATIONS

SEE PROFILE

Some of the authors of this publication are also working on these related projects:

Project The RG PTT Collaboration Pool : A Gamified Multidisciplinary Research Project View project

Project Research thought $\sim$ A way to make friends with researchers View project 


\title{
Dielectric Characterization at High Temperature of Iron Doped Potassium Strontium Niobate Ceramic by Impedance Spectroscopy
}

\author{
Caio Vinicius de Lima ${ }^{a}$, Marcos Augusto Lima Nobre ${ }^{b}$, Silvania Lanfredic \\ Laboratório de Compósitos e Cerâmicas Funcionais- LaCCeF, Fac de Ciências e Tecnologia - \\ FCT, Univ Estadual Paulista - UNESP, P.O Box 467, CEP 19060-900, Presidente Prudente-SP, \\ Brazil. \\ a caiovlima@hotmail.com, ${ }^{b}$ nobremal@fct.unesp.br, \\ csilvania@fct.unesp.br
}

\begin{abstract}
Keywords: Tetragonal Tungsten Bronze Structure, Impedance Spectroscopy, Dielectric Properties, Niobate.
\end{abstract}

\begin{abstract}
Tetragonal Tungsten Bronze structure TTB-type structure has attracted interest by the high anisotropy of the crystal structure. The dielectric characterization of iron-doped niobate of TTB-type structure, with stoichiometry $\mathrm{KSr}_{2}\left(\mathrm{Fe}_{0.25} \mathrm{Nb}_{4.75}\right) \mathrm{O}_{15-\delta}$, prepared by Modified Polyol Method was investigated. Nanocrystalline single phase powders were obtained after calcination of the precursor powder at $1150{ }^{\circ} \mathrm{C}$ for 10 hours in an oxygen atmosphere. The dielectric characterization was performed by impedance spectroscopy, from room temperature to $600{ }^{\circ} \mathrm{C}$, in the frequency range of $5 \mathrm{~Hz}$ to $13 \mathrm{MHz}$. The permittivity values obtained for $\mathrm{KSr}_{2}\left(\mathrm{Fe}_{0.25} \mathrm{Nb}_{4.75}\right) \mathrm{O}_{15-\delta}$ showed superior to the permittivity values of the $\mathrm{KSr}_{2} \mathrm{Nb}_{5} \mathrm{O}_{15}$ host structure in all temperature range investigated. At room temperature, the permittivity values (2100) of $\mathrm{KSr}_{2}\left(\mathrm{Fe}_{0.25} \mathrm{Nb}_{4.75}\right) \mathrm{O}_{15-\delta}$ is two times the permittivity values of $\mathrm{KSr}_{2} \mathrm{Nb}_{5} \mathrm{O}_{15}$. The substitution of niobium cation by iron cation in the $\mathrm{KSr}_{2} \mathrm{Nb}_{5} \mathrm{O}_{15}$ host structure showed a suppression of the ferroelectric $(\mathrm{P} 4 \mathrm{bm}) \rightarrow$ paraelectric $(\mathrm{P} 4 / \mathrm{mbm})$ phase transition.
\end{abstract}

\section{Introduction}

Ferroelectric oxides based on lead have been used by the electronic industry as actuators, transducers, piezoelectrics devices and other electromechanical components [1]. However, the toxicity of lead has led an increasing of demand for more ecofriendly alternative compounds. In this sense, the ferroelectric oxides lead-free with Tetragonal Tungsten Bronze (TTB)-type structure have shown interesting properties. In some cases, compounds of TTB-type structure have the potential to replace members of the classic set of ferroelectric ceramics, such as $\mathrm{Pb}(\mathrm{Zr}, \mathrm{Ti}) \mathrm{O}_{3}(\mathrm{PZT})$, $\left[\left(\mathrm{Pb}\left(\mathrm{Mg}_{1 / 3} \mathrm{Nb}_{2 / 3}\right) \mathrm{O}_{3}\right](\mathrm{PMN})\right.$, and [(Pb,La) $\left.(\mathrm{Zr}, \mathrm{Ti}) \mathrm{O}_{3}\right]$ (PLZT) [2]. Thus, the TTB-type compounds have spurred great technological interest in particular for microwave telecommunications involving satellite broadcasting and related devices [3]. Niobate oxides lead-free, with TTB-type structure such as $\mathrm{KSr}_{2} \mathrm{Nb}_{5} \mathrm{O}_{15}, \mathrm{NaSr}_{2} \mathrm{Nb}_{5} \mathrm{O}_{15}, \mathrm{KBa}_{2} \mathrm{Nb}_{5} \mathrm{O}_{15}, \mathrm{NaBa}_{2} \mathrm{Nb}_{5} \mathrm{O}_{15}$, and $\mathrm{K}_{3} \mathrm{Li}_{2} \mathrm{Nb}_{5} \mathrm{O}_{15}$, have been studied due to the high anisotropy of their crystalline structure [4]. The TTB structure is derived from the classical perovskite structure. Chemical formula can be write as $\mathrm{B}_{2} \mathrm{~A}_{4} \mathrm{C}_{4} \mathrm{Nb}_{10} \mathrm{O}_{30}$, where $\mathrm{B}, \mathrm{A}$, and $\mathrm{C}$ denote different sites in the crystal structure. The $\mathrm{B}$ cavities have cuboctahedral coordination, the A cavities have pentacapped pentagonal prismatic coordination, and the $C$ cavities have tricapped trigonal prismatic coordination. The cavity size decreases in the following order: $\mathrm{A}>\mathrm{B}>\mathrm{C}$. In TTB-type compounds, alkaline and/or alkaline-earth metals are located in the $\mathrm{B}$ and A sites, while only small cations like Li are found in the $\mathrm{C}$ site [5]. Taking into account the TTB structure, a wide variety of cation substitutions is possible. The cation size, its replacement fraction at different sites of the TTB structure, and the degree of disorder have significant effects on the physical properties, such as electro-optic, nonlinear, elasto-optic, pyroelectric and electrical properties [6]. In this sense, to reach these properties, the route is the engineering of degree of nonstoichiometry of compound by doping via a non-isovalent substitution cation. The cation substitution on the $\mathrm{Nb}$-site is an interesting tool to modify the electric properties of $\mathrm{KSr}_{2} \mathrm{Nb}_{5} \mathrm{O}_{15}$. This substitution leads to distortions of [NbO6] polyhedra, which appear to be necessary for the 
structural accommodation of the metal transition cations in the $\mathrm{KSr}_{2} \mathrm{Nb}_{5} \mathrm{O}_{15}$ host structure. The size and type of replacement cations at different sites of the structure and the degree of disorder have also a significant effect on the Curie temperature $\left(T_{C}\right)$, which is influenced by these parameters. In fact, the value of $T_{C}$ depends on the octahedron distortion [7] because the $T_{C}$ can be changed by application of hydrostatic pressure, which gives rise to further octahedral distortion [8]. In this work, we have studied the dielectric behavior of a newly synthesized Fe-doped $\mathrm{KSr}_{2} \mathrm{Nb}_{5} \mathrm{O}_{15}$ nonstoichiometry with formula close to $\mathrm{KSr}_{2}\left(\mathrm{Fe}_{0.25} \mathrm{Nb}_{4.75}\right) \mathrm{O}_{15-\delta}$ prepared by Modified Polyol Method. The analysis of dielectric properties was carried out by the impedance spectroscopy (IS) technique, for the first time.

\section{Materials and Methods}

Synthesis: A nanostructured $\mathrm{KSr}_{2}\left(\mathrm{Fe}_{0.25} \mathrm{Nb}_{4.75}\right) \mathrm{O}_{15-\delta}$ single-phase powder was synthesized by a Modified Polyol Method [8]. As a whole, this method gives rise to a better control of reagents, a low calcination temperature, a single-phase material, and a powder with a high specific surface area. Starting reagents for the powder synthesis via chemical route were nitric acid, $\mathrm{HNO}_{3}(99.5 \%$ Reagen), strontioum carbonate, $\mathrm{SrCO}_{3}\left(99.0 \%\right.$ Reagen), potassium carbonate, $\mathrm{K}_{2} \mathrm{CO}_{3}(99.0 \%$ Reagen), iron oxide, $\mathrm{Fe}_{2} \mathrm{O}_{3}\left(99.0 \%\right.$ Reagen), ethylene glycol, $\mathrm{HOCH}_{2} \mathrm{CH}_{2} \mathrm{OH}(98,0 \%$ Synth) and niobium oxide, $\mathrm{Nb}_{2} \mathrm{O}_{5} .3 .28 \mathrm{H}_{2} \mathrm{O}$ (CBMM-Brazil). The reagents were dissolved in nitric acid with continuous stirring in a beaker. Then $100 \mathrm{ml}$ of ethylene glycol was added. The solution was heated at $90^{\circ} \mathrm{C}$, promoting the decomposition of $\mathrm{NO}_{3}$ group, similar to the process developed in the Pechini method $[9,10]$. After the polyesterification reaction, a polymeric gel is obtained. The polymer maintained in the beaker was subjected to a primary calcination in a box-type furnace. The heating cycle was carried out via a two-step calcination starting from room temperature. In the first step, the temperature was increased with a heating rate of $10^{\circ} \mathrm{C} / \mathrm{min}$ up to $150^{\circ} \mathrm{C}$. At this point, the temperature was kept constant during $30 \mathrm{~min}$. In the second step, the temperature was increased to $300^{\circ} \mathrm{C}$ and kept constant for $1 \mathrm{~h}$. Then the furnace was cooled by nitrogen a constant flux rate of $500 \mathrm{ml} / \mathrm{min}$. The process results in partial polymer decomposition to form a resin, which consists of a brittle reticulated material. This material was deagglomerated (350 mesh) in an agate mortar and then used as a precursor. The precursor was calcined in a tube furnace in oxygen atmosphere with a flux rate of $300 \mathrm{ml} / \mathrm{min}$. The time and temperature for the precursor powder treatment were optimized to obtain $\mathrm{KSr}_{2} \mathrm{Nb}_{5} \mathrm{O}_{15}$ single-phase powders (JCPDS card number 34-0108) with high crystallinity. The calcination was carried out at $1150^{\circ} \mathrm{C}$ during $12 \mathrm{~h}$, with heating rate of $5^{\circ} \mathrm{C} / \mathrm{min}$.

\section{Dielectrical Characterization}

The powder were uniaxially pressed into pellet form of $8 \times 2 \mathrm{~mm}$ dimension. The green compacts were retreated at $1150{ }^{\circ} \mathrm{C}$ in air for $2 \mathrm{~h}$ at a heating rate of $2.0{ }^{\circ} \mathrm{C} / \mathrm{min}$. The relative densities of the samples were at around $65 \%$ of the theoretical density was reached. The aim of the thermal treatment of powder compacts at the same calcination temperature was to eliminate adsorbed gases on the particle interfaces and release compaction stress. The average crystallite sizes were assumed to be equal or very close to the average crystallite sizes of the nanostructured powders. In practice, the development of large domains and further interaction between them is blocked. Thus, the additional contribution to the dielectrical properties stemming from the cooperative phenomenon assigned to large domains is prevented. Therefore, the Curie temperature of a nanostructured powder might be derived with a high level of confidence via impedance spectroscopy. Platinum electrodes were deposited on both faces of the sample with a platinum paste coating (TR-7905-Tanaka). After complete solvent evaporation, the sample was dried at $800{ }^{\circ} \mathrm{C}$ for $30 \mathrm{~min}$.

The complex dielectric permittivity, $\varepsilon^{*}(\omega)$, can be derived from impedance data, $Z^{*}(\omega)$, $Z^{*}(\omega)=Z^{\prime}(\omega)+j Z^{\prime \prime}(\omega)$, using the following relations:

$$
\varepsilon^{*}(\omega)=\left(j \omega C_{0} Z^{*}\right)^{-1}=\varepsilon^{\prime}(\omega)+j \varepsilon^{\prime \prime}(\omega)
$$


where $\varepsilon^{\prime}(\omega)$ and $\varepsilon^{\prime \prime}(\omega)$ represent the real and imaginary parts of the permittivity and $C_{o}$ is the vacuum capacitance. Both parameters $\varepsilon^{\prime}(\omega)$ and $\varepsilon^{\prime \prime}(\omega)$ were extracted from the impedance in a conventional way, according to the following equations [11]:

$$
\begin{aligned}
& \varepsilon^{\prime}(\omega)=Z^{\prime \prime} /\left(2 \pi f \varepsilon_{\mathrm{O}} A|Z|^{2}\right) \\
& \varepsilon^{\prime \prime}(\omega)=Z^{\prime} /\left(2 \pi f \varepsilon_{\mathrm{O}} A|\mathrm{Z}|^{2}\right)
\end{aligned}
$$

where $A$ represents the geometric factor given by the relation $S / l$ and $|Z|^{2}$ represents the impedance modulus.

An alternative approach was used to calculate the permittivity from the specific capacitance, $\mathrm{C}_{\mathrm{s}}$. The $\mathrm{C}_{\mathrm{s}}$ parameter is obtained through the opposite evolution of the imaginary part of impedance, $\operatorname{Im}(Z)$, as a function of the inverse of the angular frequency, $\omega$, at high frequency range $\left(10^{5}\right.$ to 1.3 $\left.\mathrm{x} 10^{7} \mathrm{~Hz}\right)[12]$. From the $\mathrm{C}_{\mathrm{s}}$ value is derived the relative permittivity by the follows equation:

$$
\varepsilon=\frac{\mathrm{C}_{\mathrm{s}}}{\varepsilon_{0}} \times \frac{1}{\mathrm{~A}}
$$

where $\varepsilon_{0}$ is the vacuum permittivity $\left(\varepsilon_{0}=8.8542 \times 10^{-12} \mathrm{~F} / \mathrm{m}\right), 1$ the thickness of the sample and A the electrode area.

Dielectric measurements were carried out by impedance spectroscopy. Measurements were taken in the frequency range of $5 \mathrm{~Hz}$ to $13 \mathrm{MHz}$, with an applied potential of $500 \mathrm{mV}$ using an Impedance Analyzer Alpha N High Resolution Dielectric from Novocontrol GmbH, which was controlled by a personal computer. The sample was placed in a sample holder with a two-electrode configuration. Measurements were taken from room temperature to $600{ }^{\circ} \mathrm{C}$ at a heating rate equal to $2{ }^{\circ} \mathrm{C} / \mathrm{min}$ in air. A 30-min interval was used prior to thermal stabilization before each measurement. The dielectric permittivity values of $\mathrm{KSr}_{2}\left(\mathrm{Fe}_{0.25} \mathrm{Nb}_{4.75}\right) \mathrm{O}_{15-\delta}$ were determined from the equation (4).

\section{Results and Discussions}

Fig. 1 shows the dielectric permittivity curves of the $\mathrm{KSr}_{2}\left(\mathrm{Fe}_{0.25} \mathrm{Nb}_{4.75}\right) \mathrm{O}_{15-\delta}$ solid solution and of the $\mathrm{KSr}_{2} \mathrm{Nb}_{5} \mathrm{O}_{15}$ host structure, as a function of temperature. Permittivity values derived for the $\mathrm{KSr}_{2}\left(\mathrm{Fe}_{0.25} \mathrm{Nb}_{4.75}\right) \mathrm{O}_{15-\delta}$ are higher than one of the $\mathrm{KSr}_{2} \mathrm{Nb}_{5} \mathrm{O}_{15}$ ceramic at temperatures lower than $110^{\circ} \mathrm{C}$. At room temperature, the permittivity value (2100) of $\mathrm{KSr}_{2}\left(\mathrm{Fe}_{0.25} \mathrm{Nb}_{4.75}\right) \mathrm{O}_{15-\delta}$ is twice higher than the permittivity one of $\mathrm{KSr}_{2} \mathrm{Nb}_{5} \mathrm{O}_{15}$. The permittivity curve of the $\mathrm{KSr}_{2} \mathrm{Nb}_{5} \mathrm{O}_{15}$ shows a strong and broad polarization peak of high intensity at $140{ }^{\circ} \mathrm{C}$, with permittivity value equal to 1800. This peak is absent at $\mathrm{KSr}_{2}\left(\mathrm{Fe}_{0.25} \mathrm{Nb}_{4.75}\right) \mathrm{O}_{15-\delta}$ curve indicating that the development of the solid solution inhibits some kind of polarization peak. Above $200{ }^{\circ} \mathrm{C}$ both curves show similar permittivity values, as shown in inset of the Fig. 1. The maximum in the permittivity curve of the $\mathrm{KSr}_{2} \mathrm{Nb}_{5} \mathrm{O}_{15}$ has been assigned to the Curie Temperature $\left(T_{\mathrm{C}}=157^{\circ} \mathrm{C}\right)$ [13], which is accomplished of the ferroelectric $(\mathrm{P} 4 \mathrm{bm})$-paraelectric $(\mathrm{P} 4 / \mathrm{mbm})$ phase transition. In niobates of perovskite type structure, a defined or diffuse peak at permittivity curve as a function of temperature have been assigned to the structural phase transition or to a set of first-order transitions. Here, the tetragonal symmetry of $\mathrm{KSr}_{2} \mathrm{Nb}_{5} \mathrm{O}_{15}$ seems be invariant in the temperature range investigated due to the high structural anisotropy. In this sense, above of the Curie temperature, phase transitions can occur via evolution of space group, from a centrosymmetric to another centrosymmetric group.

At temperatures higher than $140{ }^{\circ} \mathrm{C}$, it is possible to hypothesize new phase transitions based on the rotation and or tilting of niobium polyhedra. However, in the permittivity curve of $\mathrm{KSr}_{2}\left(\mathrm{Fe}_{0.25} \mathrm{Nb}_{4.75}\right) \mathrm{O}_{15-\delta}$ is not observed a high polarization peak at around $140{ }^{\circ} \mathrm{C}$. 


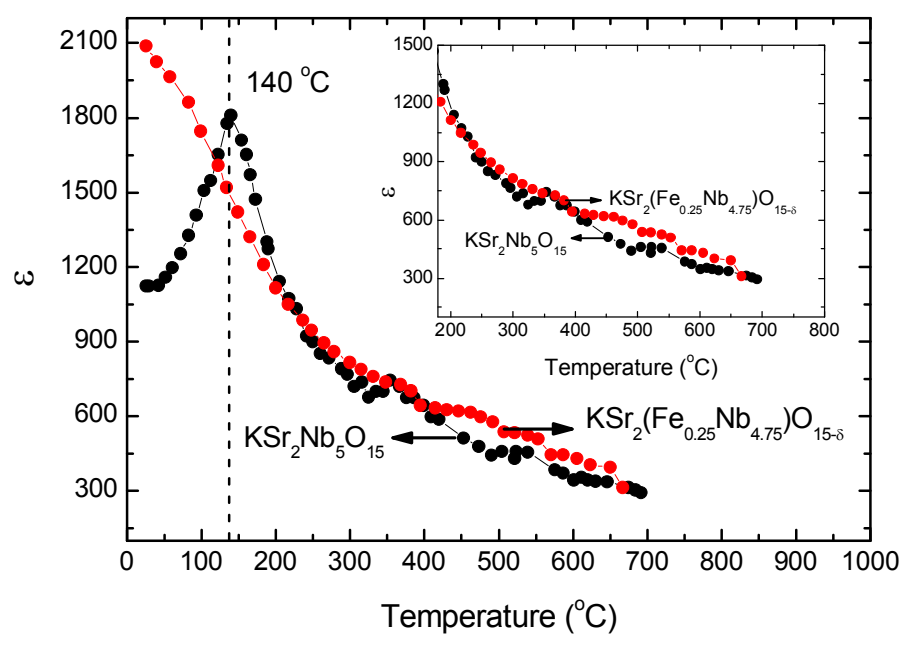

Fig. 1. Dielectric permittivity curves of $\mathrm{KSr}_{2}\left(\mathrm{Fe}_{0.25} \mathrm{Nb}_{4.75}\right) \mathrm{O}_{15-\delta}$ and $\mathrm{KSr}_{2} \mathrm{Nb}_{5} \mathrm{O}_{15}$, as a function of temperature.

Fig. 2 shows the evolution of the $\varepsilon^{\prime}(\omega)$ and $\varepsilon^{\prime \prime}(\omega)$ parameters obtained from equations (2) and (3), respectively, as a function of temperature at several frequencies. A major dispersion in the real permittivity curve $\varepsilon^{\prime}(\omega)$ (Fig. 2a), at low frequency domain ( $f=1 \mathrm{Khz}$ ), is observed with the temperature increasing. In general, these dispersions, normally observed in linear dielectric, are associated to a conduction mechanism [14]. At low temperature $\left(<400{ }^{\circ} \mathrm{C}\right)$ the permittivity curves showed independent of the temperature in all frequencies investigated. None peak was observed in the real permittivity curve $\varepsilon^{\prime}(\omega)$, in all temperature range investigated, at several frequencies, indicating absence of specific polarization phenomenon, as dipole polarization. The imaginary permittivity curve $\varepsilon^{\prime \prime}(\omega)$ as a function of temperature (Fig. 2b) shows a decreasing of magnitude with frequency increase. High $\varepsilon^{\prime \prime}(\omega)$ values are observed with the temperature increasing at low frequencies.
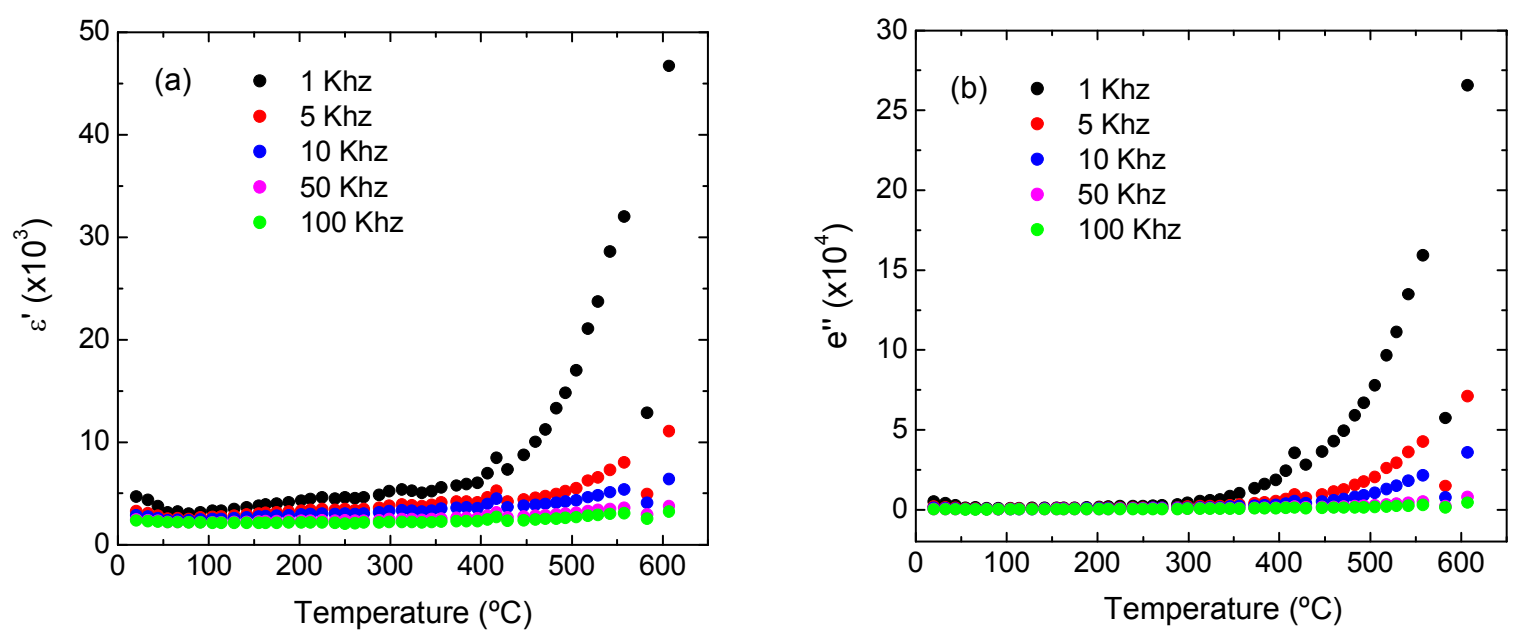

Fig. 2. Evolution of the: (a) $\varepsilon^{\prime}(\omega)$ and (b) $\varepsilon^{\prime \prime}(\omega)$ parameters as a function of temperature at several frequencies of $\mathrm{KSr}_{2}\left(\mathrm{Fe}_{0.25} \mathrm{Nb}_{4.75}\right) \mathrm{O}_{15-\delta}$.

The dispersion degree of the imaginary permittivity decreases to frequency higher than $10 \mathrm{khz}$. The dispersions in the permittivity curve, at low frequencies, may be associated to the presence of atomic defects in the structure [15]. The TTB-type structure exhibits a large number of atomic vacant sites, providing a major structural mobility and the ability to form solid solutions [16, 17]. Fig. 3 shows the graphic representation of the unit cell obtained for the $\mathrm{KSr}_{2} \mathrm{Nb}_{5} \mathrm{O}_{15}$ and $\mathrm{KSr}_{2}\left(\mathrm{Fe}_{0.25} \mathrm{Nb}_{4.75}\right) \mathrm{O}_{15-\delta}$ powders. In $\mathrm{KSr}_{2} \mathrm{Nb}_{5} \mathrm{O}_{15}$ (Fig. 3a) the pentagonal site is statistically 
occupied by equal quantities of $\mathrm{K}^{+}$and $\mathrm{Sr}^{2+}$ ions and the tetragonal site is occupied by $\mathrm{Sr}^{2+}$ ion, while in $\mathrm{KSr}_{2}\left(\mathrm{Fe}_{0.25} \mathrm{Nb}_{4.75}\right) \mathrm{O}_{15-\delta}$ (Fig. 3b) both pentagonal and tetragonal sites are occupied by equal quantities of $\mathrm{K}^{+}$and $\mathrm{Sr}^{2+}$ ions and octahedral site partially occupied by $\mathrm{Fe}^{3+}$ ions [18]. The trigonal sites are vacants. Niobium and iron atoms are coordinated by oxygen atoms, 1:6, where four oxygen atoms are placed, a priori, in the same plane of the niobium and iron atoms and another two ones above and below of the plane, respectively. It is the favorable condition to the formation of octahedron site in the structure $[16,18]$. As a whole, polyhedra of the niobium undergoe rotation and tilting. Specifically, iron cations $\left(\mathrm{Fe}^{3+}\right)$ occupy $\mathrm{Nb}(1)$ positions, which is due to the ionic radio and octahedral occupation preferential $[5,10]$. This occupation results in some distortion degree of $\left[\mathrm{NbO}_{6}\right]$ polyhedra, which appears to be necessary for the complete structural accommodation of the iron, as shown in Fig. 3(b). In this sense, both rotation and small magnitude tilting phenomena of the octahedra can be hypothesized for such an accommodation to occur. Here, it is important to highlight the participation of oxygen vacancies in the rotation and tilting phenomena because it is fundamental to the charge-compensation phenomenon required by the non-isovalent substitution of niobium cations by iron cations [16, 18]. Furthermore, at high temperature, the creation of vacancy oxygen should occur for that the electroneutrality be reached. In the high temperature domain, the non-isovalent substitution of niobium cations of the $\mathrm{KSr}_{2} \mathrm{Nb}_{5} \mathrm{O}_{15}$ structure by $\mathrm{Fe}^{3+}$ cations should be accompanied by an alteration of the stoichiometry stemming from an apparent negative excess charge that should be compensated. The compensation mechanism of the minor amount of positive charge should be based on the creation of oxygen vacancies, which occurs via the loss of oxygen from oxygen sub-lattice to atmosphere at high temperature [19].

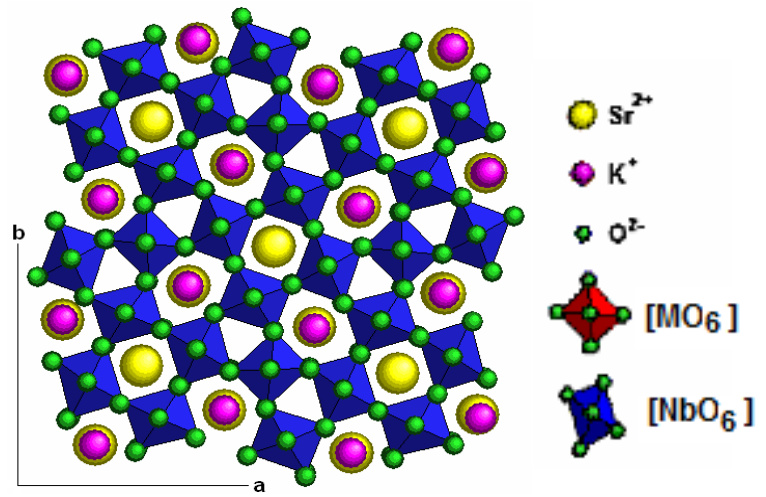

(a)

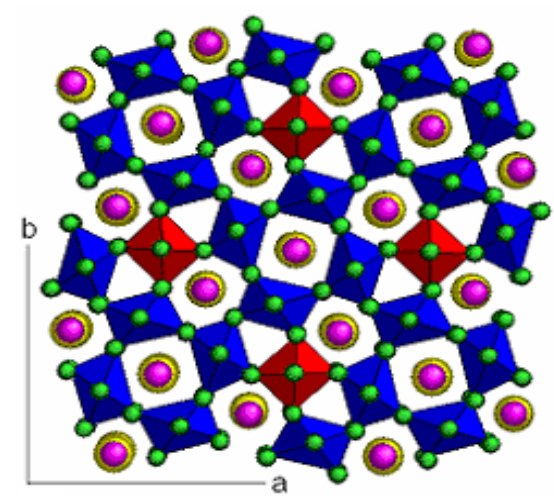

(b)

Fig. 3. Graphic representation of the unit cell obtained for the: (a) $\mathrm{KSr}_{2} \mathrm{Nb}_{5} \mathrm{O}_{15}$ and (b) $\mathrm{KSr}_{2}\left(\mathrm{Fe}_{0.25} \mathrm{Nb}_{4.75}\right) \mathrm{O}_{15-\delta}$ powders.

\section{Conclusion}

Modified Polyol method is suitable for the preparation of single phase Fe-doped $\mathrm{KSr}_{2} \mathrm{Nb}_{5} \mathrm{O}_{15}$ solid solution with TTB-type structure. The non-isovalent substitution of $\mathrm{Nb}$ by iron cations in the $\mathrm{KSr}_{2}\left(\mathrm{Fe}_{0.25} \mathrm{Nb}_{4.75}\right) \mathrm{O}_{15-\delta}$ promoted an increase of permittivity, which is two times higher than the permittivity value of $\mathrm{KSr}_{2} \mathrm{Nb}_{5} \mathrm{O}_{15}$ host structure at room temperature. Fe-doped $\mathrm{KSr}_{2} \mathrm{Nb}_{5} \mathrm{O}_{15}$ host structure leads to the suppression of the phase transition ferroelectric (P4bm) $\rightarrow$ pseudo-paraelectric $(\mathrm{P} 4 / \mathrm{mbm})$.

\section{Acknowledgements}

The authors are grateful to the Braziian research agencies: FAPESP, CNPq, Capes and UNESP/PROPe for financial support. 


\section{References}

[1] T. Iijima, S. Ito, H. Matsuda, R. Dugnani, F.K. Chang: Mater. Trans. Vol. 45 (2004), p. 233.

[2] Y.D. Hou, M.K. Zhu, C.S. Tian, H. Yan: Sensors and Actuators A. Vol. 116 (2004), p. 455.

[3] D. Kolar, S. Gaberscek, Z. Stadler, D. Suvorov: Ferroelectrics. Vol. 27 (1980), p. 269.

[4] A. Simon, J. Ravez: C.R. Chimie: Vol. 9 (2006), p. 1268.

[5] S. Lanfredi, D.H.M. Gênova, I.A.O. Brito, A.R.F. Lima, M.A.L. Nobre: J. Solid State Chem. Vol. 184 (2011), p. 990.

[6] N. Wakiya, J.K. Wang, A. Saiki, K. Shinozaki, N. Mizutani: J. Eur. Ceram. Soc. Vol. 19 (1999), p. 1071.

[7] J. Ravez: C. R. Acad. Sci. Paris. série II c (1999), p. 415.

[8] S. Lanfredi, I.A.O. Brito, C. Polini, M.A.L. Nobre: J. Appl. Spectros. Vol.79 (2012), p. 254.

[9] M. P.Pechini: U.S. Patent, No. 3.330 .697 (1967).

[10] S. Lanfredi, C.X. Cardoso, M.A.L. Nobre: Mater. Sci. Eng. B Vol. 112 (2004), p.139.

[11] M.A.L. Nobre, S. Lanfredi: Catal. Today Vol.78 (2003), p. 529.

[12] M.A.L. Nobre, S. Lanfredi: J. Phys. Chem. Solids Vol. 62 (2001), p.1999.

[13] H. El. A. Belghiti, A.Simon, P. Gravereau, A.Villesuzanne, M. Elaatmani, J. Ravez: Sol. State Sci. Vol. 4 (2002), p. 933.

[14] M.A.L. Nobre, S. Lanfredi: J. Phys. Chem. Solids. Vol. 64 (2003), p. 2457.

[15] M.A.L. Nobre, S. Lanfredi: Mater. Lett. Vol. 47 (2001), p. 362.

[16] S. Lanfredi, G. Palacio, F.S. Bellucci, C.V. Colin, M.A.L. Nobre: J. Phys. D: Appl. Phys. Vol. 45 (2012), p. 435302.

[17] S. Lanfredi, C. Darie, F.S. Bellucci, C.V. Colin, M.A.L. Nobre: Dalton Trans. Vol. 43 (2014), p. 10983.

[18] A.R.F. Lima, S. Lanfredi, M.A.L. Nobre: Quim. Nova Vol. 33 (2010), p.1071.

[19] Q. Ke, X. Lou, Y. Wang, J. Wang: Phys. Rev. B Vol. 82 (2010), p. 024102. 